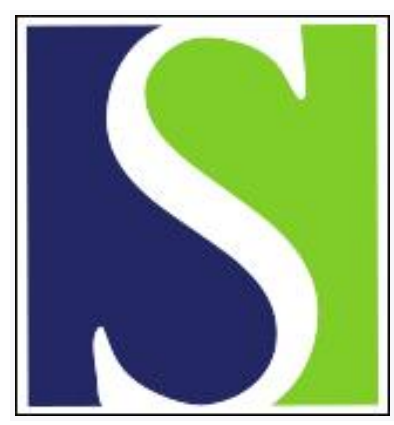

Scand J Work Environ Health 1992;18(3):169-177

https://doi.org/10.5271/sjweh.1591

Issue date: 01 Jun 1992

Adverse pregnancy outcome and childhood malignancy with reference to paternal welding exposure.

by Bonde JP, Olsen JH, Hansen KS

Affiliation: Institute of Epidemiology and Social Medicine, University of Aarhus, Denmark.

This article in PubMed: www.ncbi.nlm.nih.gov/pubmed/1615291

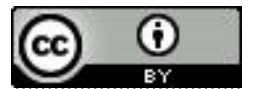




\title{
Adverse pregnancy outcome and childhood malignancy with reference to paternal welding exposure
}

\author{
by Jens Peter E Bonde, MD, ${ }^{1}$ Jørgen $\mathrm{H}$ Olsen, MD, ${ }^{2}$ Klaus S Hansen, $\mathrm{MD}^{3}$
}

\begin{abstract}
BONDE JPE, OLSEN JH, HANSEN KS. Adverse pregnancy outcome and childhood malignancy with reference to paternal welding exposure. Scand J Work Environ Health 1992;18:169-77. Welding may deteriorate spermatogenesis and increase reproductive failures. This study examines reproductive end points in a Danish cohort of 10059 metalworkers who fathered 3569 children in 1973 through 1986 . Occupational histories were gathered by postal questionnaires. Information on pregnancy outcomes and offspring was obtained by record linkage to medical registers. The occurrence of reduced birthweight, preterm delivery, infant mortality, and congenital malformation was not increased among children at risk from paternal welding exposure in comparison with children not at risk. The overall incidence of childhood malignancies among 23264 children born in 1968 through 1986 with a total of 259113 person-years of followup was equal to national rates (relative risk $0.97,95 \%$ confidence interval $0.63-1.42$ ). However, pregnancies preceding a birth at risk from paternal exposure to stainless steel welding were more often terminated by spontaneous abortion (odds ratio 1.9, 95\% confidence interval 1.1-3.2). This finding needs cautious interpretation and should be further investigated in future studies.
\end{abstract}

Key terms: birth characteristics, birth defect, congenital malformation, reproductive failure, spontaneous abortion.

Several chemical and physical hazards in the workplace may adversely affect the reproductive capability of male employees. While many specific occupational exposures causing reduced semen quality and impaired fertility have been identified (for a review, see references 1 and 2), knowledge about paternal exposure causing adverse pregnancy outcome and childhood malignancy is very limited (3-8). So far no environmental paternal teratogen or carcinogen has been identified in humans. In recent years several studies have addressed this issue (6-14). In general, two lines of evidence support the biological plausibility of paternally induced adverse pregnancy outcomes and childhood carcinogenesis. First of all, animal experiments document that X-ray treatment and the administration of genotoxic substances to male animals before mating can produce a broad category of adverse pregnancy outcomes, including malformations and - less convincing - malignant disease in the litter (3). The second line of evidence links poor semen quality in humans with an increased rate of spontaneous abortion $(15,16)$. Several studies suggest that welding is detrimental to male reproductive capability, causing reduced semen quality $(17,18)$ and fertility $(19,20)$.

\footnotetext{
1 Institute of Epidemiology and Social Medicine, University of Aarhus, Denmark, and Department of Occupational Medicine, University Hospital of Aarhus, Denmark.

2 Danish Cancer Register, Copenhagen, Denmark.

${ }^{3}$ Institute of Community Medicine, University of Odense, Denmark.
}

Reprint requests to: Dr JPE Bonde, Department of Occupational Medicine, University Hospital of Aarhus, Nørrebrogade 37-39, Aarhus, D-8000 Aarhus C, Denmark.
Stainless steel welders can be exposed to high levels of hexavalent chromium and nickel. These substances have mutagenic, genotoxic, and carcinogenic actions in both humans and animals $(21,22)$. An increased rate of sister chromatid exchanges and chromosome aberration in peripheral lymphocytes of stainless steel welders has been reported by several research groups (22). However, detrimental effects on semen quality and fertility among welders seem to be the most attributable to mild steel welding $(18,20)$.

This study explores the broad hypothesis that wives of welders - and in particular stainless steel welders with a documented genotoxic exposure in the proper time period - have an increased risk of adverse pregnancy outcomes and that welders' offspring have increased risk of childhood malignancies. Achievement of exact knowledge in this research area obviously must involve research in multiple steps. At the present state of knowledge it is probably not justified to put forward hypotheses concerning specific outcomes (eg, type of malformation or type and location of cancer). The objective of this study was to evaluate whether more specific hypotheses should be focused on in future studies.

\section{Subjects and methods}

The main steps in identifying the study populations and collecting the data are outlined in figure 1 .

\section{Cohort of fathers}

Pregnancy outcome study, metalworker cohort. The source population for the study of pregnancy outcome 


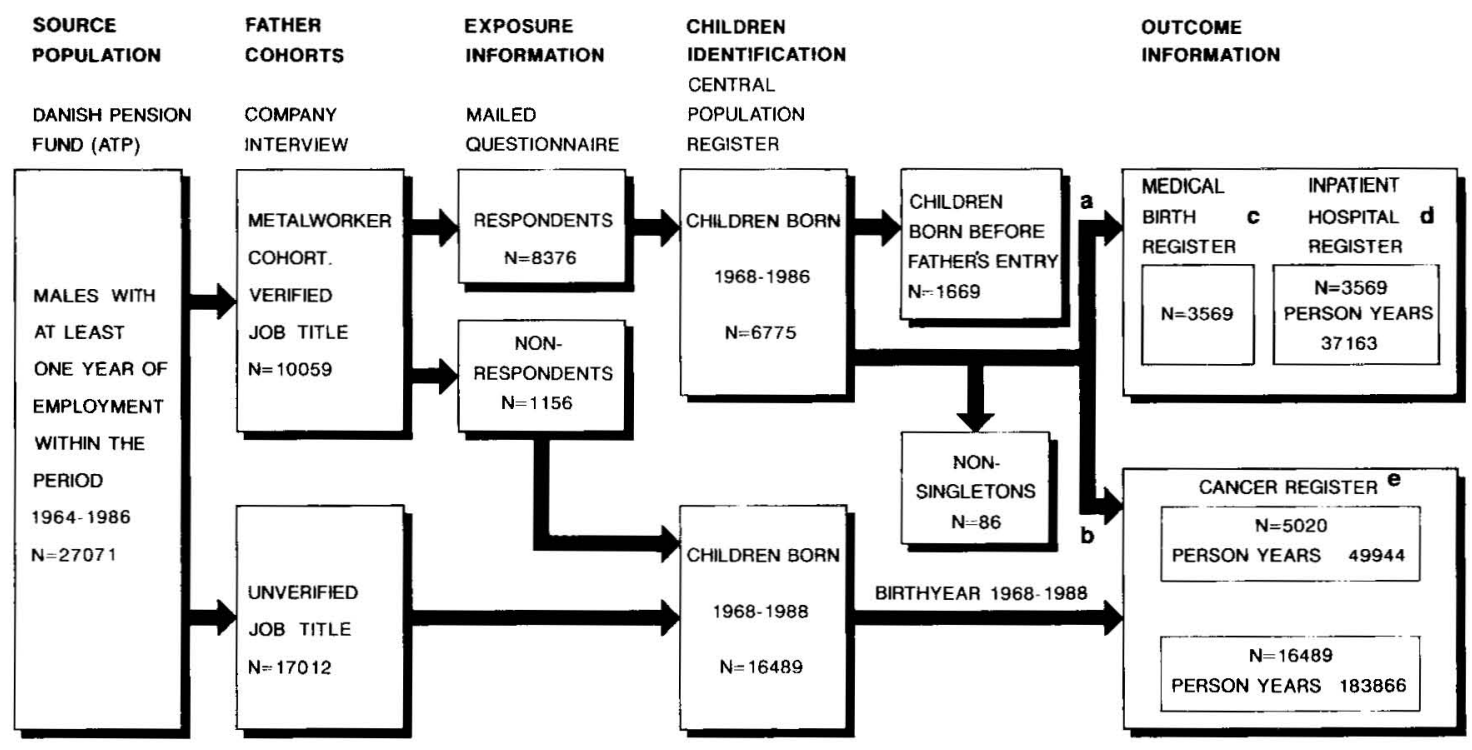

Figure 1. Identification of the study populations and the collection of the exposure and outcome information. [a=children with birth year 1973-1986 (inclusive), $b=$ children with birth year 1968-1986 (inclusive), $c$ = including records from the death certificate register, $\mathrm{d}=$ follow-up period 1 January 1977-31 December 1988, e = follow-up period 1 April 1968-31 December 1987]

was a cohort of 10059 Danish male production workers employed at Danish stainless steel or mild steel manufacturing companies (74 companies employing about $60 \%$ of all Danish stainless steel welders and five large mild steel companies) for a minimum of one year within the period April 1964 through December 1984. This cohort with open entry and closed exit was created from records, in the Danish Pension Fund, of men ever employed as production workers. In a subsequent step data on job title and department of potential cohort members were obtained at each of the 79 companies by standard interviews with managers, foremen, and long-term workers. Only subjects with verified employment as mild steel welders, stainless steel welders, stainless steel grinders, or nonwelding and nongrinding production workers (eg, turners, fitters, warehousemen, but not apprentices or craftsmen) were admitted into the cohort.

Childhood malignancy study, company cohort. The source population for studying the risk of malignant disease in offspring comprised the entire population of 27071 Danish men who, according to records in the Danish Pension Fund, had been employed at the aforementioned companies for a minimum of one year within the period April 1964 through December 1984 (figure 1). Besides the 10059 metalworkers with verified job titles and departments, this group also included metalworkers with unverified job title or department, other production workers, and white-collar workers.

\section{Information on exposure}

During the autumn of 1986 members of the metalworker cohort were mailed a questionnaire on lifetime occupational exposures and smoking and drinking habits. Responses were received from 8376 cohort members (response rate $85 \%$ ). Information on welding mild steel and stainless steel was obtained from a separate series of questions in the questionnaire filled out by the cohort members (fathers). For each type of welding workers were asked to record their first and last years worked (recorded as calendar years). All years within the interval spanning first and last years worked were considered exposed years. The interval spanning first and last years worked is a useful approximation of the actual years worked (20).

Exposure to nickel and hexavalent chromium in stainless steel welding depends substantially on the welding methods employed. Manual metal arc (MMA) welding confers much greater exposure to these metals than does the tungsten inert gas (TIG) method (21). Respondents were asked to note the welding methods used in each of three periods (ie, 1960-1969, 19701979 and 1980-1986). A year was considered exposed to MMA if it fell within a period in which MMA welding had been used. The following arbitrary exposure score for stainless steel welding was constructed: $0=$ unexposed; 1 = stainless steel welding, TIG method; 2 = stainless steel welding, MMA method. Scores thus defined constituted the basis for an exposure-response evaluation of pregnancy outcomes at risk from stainless steel welding. The total number of years with welding work preceding conception was used in the examination of the effects of accumulated exposure. 
Questionnaire information on first and last year of smoking was also obtained. All intervening years were considered exposed to smoking. Cohort members whose current and previous consumption of alcoholic beverages exceeded ten beers, five glasses of wine, or five drinks of liquor per week comprised a "high alcohol-exposed" group, while other subjects were classified as "the low alcohol-exposed" group.

Questionnaire information was not obtained from members of the company cohort not included in the cohort of metalworkers (figure 1).

\section{Identifying offspring}

Liveborn children of all the cohort members were identified from records in the Danish Central Population Register. Cohort members were identified by the official Danish personal number, a 10-digit number unique to all subjects with Danish citizenship. A verification code contained in the records of the Register indicates the reliability of the cross-references between parents and their children. The parent-child cross-reference can be considered complete and reliable for children born in 1968 and subsequent years (20). During the period 1968-1986 inclusive the 8376 questionnaire-responding cohort members had fathered 6775 children, and the 18168 employees in the remaining part of the company cohort had had 16489 children. The parent-child cross-reference had been verified in 98.7 and $99.1 \%$, respectively, of the cases. When a child is adopted, the biological parent-child cross-reference is canceled. It can be estimated that approximately $1.6 \%$ of the children in the actual cohort were not biologically related to the cohort members (20). This source of misclassification is very limited and is not likely to bias the results of a delivery outcome study.

Children who were born before the years in which the fathers were admitted into the cohort of metalworkers and twins/triplets were excluded from the metalworker offspring cohort, which finally comprised 3569 children for the analysis of pregnancy outcome and 5020 children for the analysis of malignant disease (figure 1).

\section{Information on pregnancy outcome and maternal characteristics}

By record linkage to the Danish Medical Birth Register information was obtained on births of children fathered by metalworkers in Denmark in 1973 (the year the register was established) through 1986 . The children were identified in the Register by their personal identification numbers. From the Register, information was collected on the following outcome variables: gender, birthweight, birth length, pregnancy week of birth, number of spontaneous and induced abortions preceding the birth (from 1978 only), and congenital malformation; and on the following birth-specific characteristics were obtained: maternal age and parity, medical specialization of maternity ward, geographic place of birth, maternal occupation, and marital status. These data are reported to the Medical Birth Register by the midwife shortly after birth. The birthweight is recorded in classes spanning $250 \mathrm{~g}$ (1973 through 1981) or $10 \mathrm{~g}$ (1982 through 1987).

Only congenital malformations observed at birth or during the very first days of life are recorded in the Medical Birth Register. In particular asymptomatic malformations of internal organs are not recognized at birth. The national prevalence rate of all malformations recorded in the Register averaged $1.9 \%$ during the period 1980 through 1983 (23); this value is low in comparison with rates reported when other methods for the detection of malformations are used [3-4\% (24)]. To minimize the incompleteness of registration of congenital malformations, two additional data sources were used. For children who died within the first year of life, data were derived from the death certificate. Furthermore, cases with congenital malformation were identified among children admitted to inpatient treatment at a Danish hospital during the period 1977 (the year the National Inpatient Hospital Register was founded) through 1988 . Only children born in 1973 or subsequent years were included in the register linkage procedure. In all three data bases congenital malformations were coded according to the International Classification of Diseases, eighth revision (code numbers 740-759). Only one congenital malformation code was assigned to each child. In case the data source contained two or more diagnoses of malformations, only the first recorded malformation was assigned. In case the diagnosis differed between the three data sources, the birth certificate was given first priority and the hospital register second priority. Figure 2 reveals the number of malformations identified by each data source.

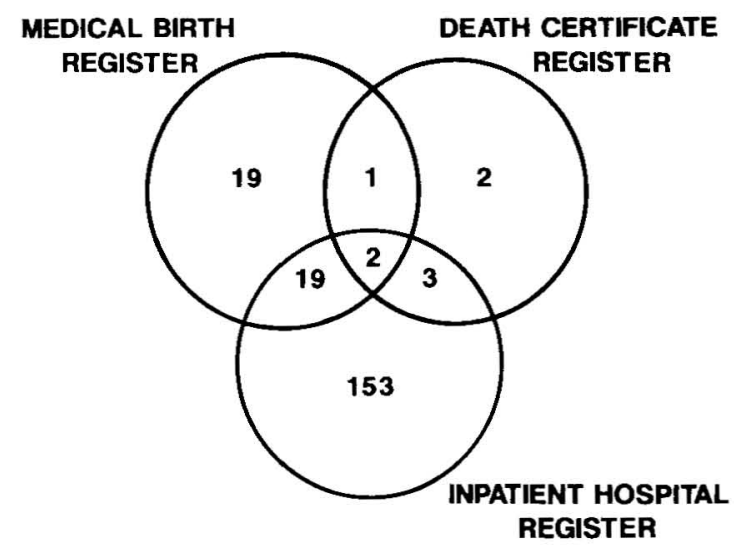

Figure 2. Children with congenital malformation by source of information. A total of 177 children with congenital malformation was traced; only two children were traced in all three registers; $19+2=21$ were traced in both the Medical Birth Register and the Inpatient Hospital Register. 


\section{Information on childhood malignancies}

Among the liveborn children fathered by members of the company cohort in 1968 and subsequent years, cases with cancer were identified through data linkage with the files in the Danish Cancer Register. The linkage was completed by use of a previously established procedure (25). The Cancer Register receives reports of malignant and related diseases from clinical departments when a cancer is diagnosed and when changes in initial diagnosis occur. These reports are supplemented by reports from pathology departments on all malignancies discovered, including cancers first recognized at autopsy and by information based on death certificates only. Although the Cancer Register started reporting cancer incidence data on a nationwide basis already in 1943, the incompleteness and unreliability of parent-child relations before 1968 makes the inclusion of children born before 1968 inappropriate.

\section{Analysis and statistical methods}

The unit of observation was either a pregnancy (analysis of abortions) or a liveborn child (all other analyses). Children were classified as at risk or not at risk according to paternal welding exposure in the calendar year preceding the birth year so that effects on any stage of spermiogenesis ( 3 months) and the period of gestation ( 9 months) could be allowed for. An entire calendar year (January 1-December 31) was designated as exposed even if welding had been undertaken only during part of the year. The questionnaire information did not allow for a more-detailed categorization. Births occurring after at least 12 months without welding work were not considered at risk from exposure. Few children were at risk from stainless steel welding only $(\mathrm{N}=283)$. In the presentation of the results this group was pooled with children at risk from both stainless steel and mild steel welding $(\mathrm{N}=1034)$. Children designated at risk from mild steel welding were at risk from mild steel welding only.

Each childbirth was identified with the time-specific value of the following paternal and maternal characteristics: maternal age, maternal parity $(0,1,2, \geq 3)$, maternal occupation (salaried employee/wage-earning employee/housewife), marriage (yes/no), birthplace (urban/rural classified according to a code developed by Danmarks Statistik), maternity ward (obstetric hospital department or not), paternal smoking (yes/no), and paternal alcohol beverage consumption

Table 1. Birth year of the children and parental characteristics at time of birth according to the risk category.

\begin{tabular}{|c|c|c|c|c|c|c|c|c|c|c|c|c|}
\hline & \multicolumn{4}{|c|}{$\begin{array}{l}\text { Children at risk from } \\
\text { stainless steel welding } \\
\qquad(N=1317)\end{array}$} & \multicolumn{4}{|c|}{$\begin{array}{l}\text { Children at risk from } \\
\text { mild steel welding } \\
\qquad(\mathrm{N}=924)\end{array}$} & \multicolumn{4}{|c|}{$\begin{array}{l}\text { Children not at risk } \\
\qquad(N=1328)\end{array}$} \\
\hline & $N$ & $\%$ & Mean & SD & $\mathrm{N}$ & $\%$ & Mean & SD & $\mathbf{N}$ & $\%$ & Mean & SD \\
\hline \multicolumn{13}{|l|}{ Birth year of children } \\
\hline $\begin{array}{l}1973-1977 \\
1978-1982 \\
1983-1986\end{array}$ & $\dot{s}$ & $\begin{array}{l}36.5 \\
29.6 \\
33.9\end{array}$ & $\dot{.}$ & $\dot{.}$ & $\dot{\cdot}$ & $\begin{array}{l}45.4 \\
29.6 \\
25.0\end{array}$ & $\dot{.}$ & $\dot{r}$ & $\dot{.}$ & $\begin{array}{l}33.8 \\
31.6 \\
34.6\end{array}$ & $\dot{.}$ & $\dot{.}$ \\
\hline Number of fathers ${ }^{a}$ & 999 & 75.9 & $\cdot$ & . & 690 & 74.7 & . & $\cdot$ & 953 & 71.8 & $\cdot$ & $\cdot$ \\
\hline Maternal age (years) & $\cdot$ & $\cdot$ & 26.1 & 4.3 & $\cdot$ & $\cdot$ & 25.9 & 4.4 & $\cdot$ & $\cdot$ & 26.4 & 4.7 \\
\hline Paternal age (years) & . & . & 29.5 & 4.8 & $\cdot$ & . & 29.6 & 4.8 & $\cdot$ & . & 30.3 & 5.3 \\
\hline \multicolumn{13}{|l|}{ Maternal parity } \\
\hline $\begin{array}{l}\text { Parity } 0 \\
\text { Parity } 1 \\
\text { Parity } 2 \\
\text { Parity } \geq 3\end{array}$ & $\dot{:}$ & $\begin{array}{r}42.5 \\
40.2 \\
12.6 \\
4.7\end{array}$ & $\dot{.}$ & $\dot{.}$ & $\dot{5}$ & $\begin{array}{r}41.8 \\
40.2 \\
12.8 \\
5.2\end{array}$ & $\dot{.}$ & $\dot{.}$ & $\dot{.}$ & $\begin{array}{r}36.9 \\
40.8 \\
15.1 \\
7.2\end{array}$ & . & $\dot{.}$ \\
\hline Marriage rate & $\cdot$ & 74.9 & . & $\cdot$ & $\cdot$ & 77.7 & . & . & $\cdot$ & 75.9 & . & $\cdot$ \\
\hline \multicolumn{13}{|l|}{ Maternal occupation ${ }^{b}$} \\
\hline $\begin{array}{l}\text { Salaried employee } \\
\text { Wage-earning employee } \\
\text { Housewife }\end{array}$ & $\dot{5}$ & $\begin{array}{l}36.7 \\
33.1 \\
30.2\end{array}$ & $\dot{.}$ & $\dot{.}$ & $\dot{.}$ & $\begin{array}{l}34.9 \\
35.1 \\
30.0\end{array}$ & $\dot{.}$ & $\dot{.}$ & $\dot{.}$ & $\begin{array}{l}31.9 \\
34.0 \\
34.1\end{array}$ & $\dot{.}$ & $\dot{.}$ \\
\hline \multicolumn{13}{|l|}{ Child's geographic birthplace } \\
\hline $\begin{array}{l}\text { Urban area } \\
\text { Rural area }\end{array}$ & $\dot{.}$ & $\begin{array}{l}48.0 \\
52.0\end{array}$ & : & $\dot{.}$ & $\dot{.}$ & $\begin{array}{l}31.4 \\
68.6\end{array}$ & . & $\dot{\cdot}$ & $\dot{.}$ & $\begin{array}{l}45.6 \\
54.4\end{array}$ & $\dot{.}$ & $\dot{.}$ \\
\hline \multicolumn{13}{|l|}{ Maternity ward } \\
\hline $\begin{array}{l}\text { Obstetric department } \\
\text { Other department or home }\end{array}$ & $\dot{.}$ & $\begin{array}{l}75.8 \\
24.2\end{array}$ & $\dot{.}$ & $\dot{.}$ & $\dot{\cdot}$ & $\begin{array}{l}68.7 \\
31.3\end{array}$ & $\dot{.}$ & $\cdot$ & $\dot{.}$ & $\begin{array}{l}75.1 \\
24.9\end{array}$ & $\dot{.}$ & $\dot{.}$ \\
\hline Paternal smoking & $\cdot$ & 68.6 & $\cdot$ & $\cdot$ & $\cdot$ & 65.9 & $\cdot$ & $\cdot$ & $\cdot$ & 64.1 & $\cdot$ & $\cdot$ \\
\hline $\begin{array}{l}\text { Paternal alcoholic beverage } \\
\text { consumption high }\end{array}$ & . & 7.4 & . & . & - & 8.6 & . & . & $\cdot$ & 4.4 & $\cdot$ & $\cdot$ \\
\hline
\end{tabular}

a A total of 2413 cohort members had fathered 3569 children. The number of fathers within each exposure category does not sum to 2413 because some fathers contributed to two or more exposure categories.

b Not recorded during 1981-1986 inclusive; 893 observations missing; self-employed $(N=23)$ and assistant spouse $(N=13)$ included in the salaried employee category. 
(high/low). Information concerning maternal occupation was only available during the period 1973-1980 (65\% of the births occurring during this period). For $39 \%$ of the children born in 1981 through 1986, information on the mothers' occupation was transferred from records from the 1973-1980 period on the assumption that no change in occupation had taken place. Detailed information concerning maternal occupation and life-style factors was not available. The distribution of potential confounding determinants and follow-up time by risk categories is given in table 1 .

Pregnancy outcomes. The occurrence of adverse delivery outcome (reduced birthweight and length, preterm delivery, and death within first year of life) and change of gender ratio were analyzed by logistic regression conditional on paternal welding exposure and potential confounding determinants. Risk of spontaneous abortion was analyzed with the use of information on number of spontaneous abortions preceding births in 1978 (the year information from midwives concerning previous abortion was included in the Register) and subsequent years. This analysis was restricted to births with one preceding pregnancy. A pregnancy was considered at risk from paternal welding exposure if the corresponding birth was categorized at risk.

An approximation of relative risk, the odds ratio (OR), was computed from the logistic regression coefficients (26). The $95 \%$ confidence interval $(95 \% \mathrm{CI})$ of the OR was derived from the standard errors of the regression coefficients. All potential confounding determinants were included in the logistic regression models regardless of the level of significance or magnitude of effect on the dependent variable unless otherwise specified in the reporting of the results. Outcome variables in continuous form (birthweight, birth length and pregnancy week of birth) were analyzed by multiple linear regression procedures (26).

Congenital malformation. The observed number of cases with congenital malformation among children at risk from exposure were compared with the numbers to be expected from the occurrence of malformations among children not at risk, time of follow-up in the National Inpatient Register being taken into account. The follow-up period spanned the date of birth and 31 December 1988 or date of diagnosis, death, or emigration. The levels of significance, relative risk, and $95 \%$ confidence intervals were computed by approximate Poisson regression with adjustment for the specialization of maternity ward, age, and gender of the child (26). The influence of other potential confounders (age of parents, maternal parity, paternal smoking and alcoholic beverage consumption, occupational status of the mother, and living area) were evaluated with logistic regression models.

Childhood malignancy. The period of follow-up for cancer occurrence was taken from the date of birth to the date of death, date of emigration or 31 December 1987, whichever came first. The total number of cancers registered among the children were recorded for each site, defined by the seventh revision of the International Classification of Diseases. The national incidence rates for site-specific tumors by gender and five-year age and calendar-year groups were applied to the appropriate person-years under observation to obtain the number of cancers expected had the children under study experienced the same rates as prevailed in the general childhood population in Denmark. The tests of significance and the $95 \%$ confidence intervals for the relative risk, taken as the ratio of observed-to-expected cancers, were calculated by use of the exact Poisson probabilities (27).

\section{Results}

\section{Pregnancy outcome}

No change in the gender ratio or difference in the prevalence of adverse delivery outcomes was found for children at risk from paternal welding exposure in comparison with those not at risk (table 2). The distribu-

Table 2. Crude risk estimates with $95 \%$ confidence intervals for adverse birth characteristics among children at risk from paternal welding exposure and those not at risk. The adjusted risk estimates were very close to crude risk estimates and are not given. (OR=odds ratio, $95 \% \mathrm{Cl}=95 \%$ confidence interval)

\begin{tabular}{|c|c|c|c|c|c|c|c|c|c|c|c|c|c|c|c|}
\hline \multirow[t]{2}{*}{ Exposure category } & \multicolumn{3}{|c|}{ Gender female } & \multicolumn{2}{|c|}{$\begin{array}{l}\text { Birthweight } \\
\text { (g) }\end{array}$} & \multicolumn{3}{|c|}{$\begin{array}{l}\text { Birthweight } \\
\leq 2500 \mathrm{~g}\end{array}$} & \multirow{2}{*}{$\begin{array}{c}\begin{array}{c}\text { Gestation } \\
\text { length } \\
\text { (weeks) }\end{array} \\
\text { Mean SD }\end{array}$} & \multicolumn{3}{|c|}{ Preterm delivery ${ }^{a}$} & \multicolumn{3}{|c|}{ Neonatal mortality } \\
\hline & $\%$ & OR & $95 \% \mathrm{Cl}$ & Mean & SD & $\%$ & OR & $95 \% \mathrm{Cl}$ & & $\%$ & OR & $95 \% \mathrm{Cl}$ & $\%$ & OR & $95 \% \mathrm{Cl}$ \\
\hline $\begin{array}{l}\text { Children at risk from } \\
\text { stainless steel welding } \\
(\mathrm{N}=1317)\end{array}$ & 46.9 & 0.87 & $0.74-1.01$ & 3368 & 588.4 & 6.3 & 1.01 & $0.74-1.38$ & $39.6 \quad 1.9$ & 5.1 & 1.32 & $0.91-1.91$ & 0.8 & 0.99 & $0.43-2.30$ \\
\hline $\begin{array}{l}\text { Children at risk from } \\
\text { mild steel welding } \\
\text { (N=924) }\end{array}$ & 48.8 & 0.94 & $0.79-1.11$ & 3434.5 & 568.4 & 5.6 & 0.89 & $0.63-1.28$ & 39.81 .6 & 2.8 & 0.71 & $0.44-1.45$ & 0.2 & 0.26 & $0.06-1.18$ \\
\hline $\begin{array}{l}\text { Children not at risk } \\
(\mathrm{N}=1328)\end{array}$ & 50.5 & 1.00 & . & 3379.8 & 595.0 & 6.3 & 1.00 & . & $39.6 \quad 2.1$ & 3.9 & 1.00 & . & 0.8 & 1.00 & . \\
\hline
\end{tabular}

a Delivery more than three weeks preterm.

b 1034 children were at risk from mild steel welding also.

c Children at risk from mild steel welding only. 
tions of birth length (figures not given) and birthweight were almost identical in the three exposure groups. Within the group of births at risk from paternal stainless steel welding exposure, the risk of reduced birth- weight and preterm delivery was not increased in the subgroup thought to be highly exposed (MMA welding) in comparison with those lowly exposed (TIG welding), nor was the risk increased for long-term

Table 3. Risk estimates for spontaneous abortion in pregnancies preceding the delivery of liveborn children in 1978 through 1987, according to paternal welding exposure. Restriction was made to deliveries with one preceding pregnancy. (OR $=0$ odds ratio, $95 \% \mathrm{Cl}=95 \%$ confidence interval)

\begin{tabular}{|c|c|c|c|c|c|c|c|c|c|c|c|c|c|c|}
\hline \multirow[b]{3}{*}{$\begin{array}{l}\text { Spontaneous } \\
\text { abortion }\end{array}$} & \multicolumn{6}{|c|}{$\begin{array}{l}\text { Pregnancies at risk from } \\
\text { stainless steel welding }(\mathrm{N}=302)\end{array}$} & \multicolumn{6}{|c|}{$\begin{array}{l}\text { Pregnancies at risk from } \\
\text { mild steel welding }(N=184)\end{array}$} & \multicolumn{2}{|c|}{$\begin{array}{l}\text { Pregnancies } \\
\text { not at risk } \\
(\mathrm{N}=322)\end{array}$} \\
\hline & $N$ & $\%$ & OR & $95 \% \mathrm{Cl}$ & $\begin{array}{l}\text { Ad- } \\
\text { justed } \\
\mathrm{OR}^{\mathrm{a}}\end{array}$ & $\begin{array}{l}95 \% \mathrm{Cl} \\
\text { for ad- } \\
\text { justed } \\
\text { OR }\end{array}$ & $\mathrm{N}$ & $\%$ & OR & $95 \% \mathrm{Cl}$ & $\begin{array}{l}\text { Ad- } \\
\text { justed } \\
\mathrm{OR}^{\mathrm{a}}\end{array}$ & $\begin{array}{l}95 \% \mathrm{Cl} \\
\text { for ad- } \\
\text { justed } \\
\text { OR }\end{array}$ & $\mathrm{N}$ & $\%$ \\
\hline & 38 & 12.6 & 1.9 & $1.1-3.2$ & 2.0 & $1.1-3.5$ & 12 & 7.1 & 1.0 & $0.5-2.0$ & 1.1 & $0.5-2.4$ & 23 & 7.1 \\
\hline $\begin{array}{l}\text { Induced } \\
\text { abortion }\end{array}$ & 45 & 15.2 & 2.1 & $1.2-3.4$ & 2.3 & $1.3-4.0$ & 25 & 13.6 & 1.8 & $1.0-3.2$ & 2.3 & $1.2-4.5$ & 26 & 8.1 \\
\hline
\end{tabular}

a OR adjusted for effects of maternal age, birthplace, marital status, and paternal smoking and drinking habits.

Table 4. Observed and expected numbers of children with congenital malformations among children at risk and not at risk from paternal welding exposure.

\begin{tabular}{|c|c|c|c|c|c|}
\hline \multirow[t]{2}{*}{ Type of malformationa } & \multicolumn{2}{|c|}{$\begin{array}{c}\text { Children at risk from } \\
\text { stainless steel welding } \\
(\mathrm{N}=1317) \\
\text { (years of follow-up: } 13437 \text { ) }\end{array}$} & \multicolumn{2}{|c|}{$\begin{array}{l}\text { Children at risk from } \\
\text { mild steel welding } \\
(\mathrm{N}=924) \\
\text { (years of follow-up: } 10395 \text { ) }\end{array}$} & \multirow{2}{*}{ 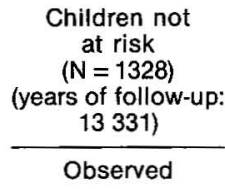 } \\
\hline & Observed & Expected ${ }^{b}$ & Observed & Expected ${ }^{b}$ & \\
\hline Nervous system $(740-743)$ & 3 & . & - & . & - \\
\hline Eye, ear, face and neck $(744-745)$ & 12 & 12.1 & 5 & 9.4 & 12 \\
\hline Cardiovascular system (746-747) & 2 & $11.1^{*}$ & 1 & $8.6^{*}$ & 11 \\
\hline Respiratory organs (748) & 4 & $\therefore$ & 1 & $\dot{8}$ & $\overline{1}$ \\
\hline Cheilognatopalatoschisis (749) & 1 & 1.0 & 1 & 0.8 & 1 \\
\hline Digestive tract $(750-751)$ & 5 & 7.1 & 4 & 5.5 & 5 \\
\hline Genital system (752) & 19 & 24.2 & 8 & $18.7^{*}$ & 24 \\
\hline Urinary organs (753) & 1 & 3.0 & 2 & 2.3 & 4 \\
\hline Limb deformities (754-755) & 20 & 20.2 & 12 & 15.6 & 20 \\
\hline Other malformations (756-759) & 8 & 9.1 & 3 & 7.0 & 9 \\
\hline $\begin{array}{l}\text { All malformations } \\
\text { Adjusted OR }\end{array}$ & $\begin{array}{r}75 \\
0.81\end{array}$ & $\begin{array}{l}87.7 \\
(0.62-1.06)\end{array}$ & $\begin{array}{r}37 \\
0.57\end{array}$ & $\begin{array}{l}67.8^{* *} \\
(0.41-0.80)\end{array}$ & $\begin{array}{l}87 \\
1.0\end{array}$ \\
\hline
\end{tabular}

a Codes of the International Classification of Diseases, eighth revision, in parentheses.

b Number of expected cases calculated according to occurrence among children not at risk.

c Odds ratio adjusted for the potential confounding effect of age of parents, maternal parity, degree of specialization of hospi-

tal department, paternal alcoholic beverage consumption and smoking habits, occupational status of the mother, and living area $(95 \%$ confidence interval in parentheses).

* $P<0.05,{ }^{* *} P<0.01$.

Table 5. Relative risk of malignant disease in children fathered by metalworkers.

At risk from stainless steel welding ${ }^{a}$ At risk from mild steel welding ${ }^{b}$ Not at risk from welding Metal industryc

$\begin{array}{rrrrrrr}\begin{array}{c}\text { Number of } \\ \text { children }\end{array} & \begin{array}{c}\text { Number of } \\ \text { person-years }\end{array} & \begin{array}{c}\text { Cases of malignant } \\ \text { disease }\end{array} & \begin{array}{c}\text { Relative } \\ \text { risk }\end{array} & \begin{array}{c}95 \% \\ \text { observed Expected }\end{array} & & \\ \text { interval } \\ \text { intence }\end{array}$

\footnotetext{
a Including welders who also weld mild steel.
}

b Including welders who also weld stainless steel.

c Risk among children fathered by members of company cohort (see figure 1) but excluding metal workers with information on exposure. 
stainless steel welding ( $>6$ years) when it was compared with short-term stainless steel welding $(\leq 6$ years).

The risk of spontaneous abortion in previous pregnancies was moderately increased for pregnancies at risk from paternal exposure to stainless steel welding, but not for those at risk from paternal exposure to mild steel welding (table 3). Adjusting for potential confounding effects of maternal age and occupation, birthplace, marital status, and paternal smoking and drinking habits did not change the observed relations (table 3). The risk estimate was higher for pregnancies at risk from MMA stainless steel welding (OR 1.99, $95 \%$ CI $1.07-3.69, \mathrm{~N}=173$ ) than for those at risk from TIG stainless steel welding (OR 1.71, 95\% CI $0.84-3.39, \mathrm{~N}=129$ ), a finding indicating an exposureresponse relation (chi-square for trend 5.2, degree of freedom $1, P=0.022$ ). The number of years with paternal stainless steel welding experience did not influence the rate of spontaneous abortion. No data on the actual date of the spontaneous abortion preceding the index birth were available. This lack may have introduced a misclassification of the exposure assigned according to exposure of the birth. For this reason an analysis was undertaken including only births with either exposure or nonexposure through all three years preceding the birth. The risk estimate for spontaneous abortion among stainless steel welders was unchanged (OR 1.7, 95\% CI $0.9-3.1, \mathrm{~N}=519$ ).

\section{Congenital malformation}

The overall occurrence of congenital malformations was reduced, although not statistically significantly, for the children at risk from stainless steel welding (regardless of mild steel welding) and was significantly reduced for the children at risk from mild steel welding [mild steel welding only (table 4)] even after adjustment for several potentially confounding characteristics. Nothing could be inferred about the occurrence of malformations among the children at risk from stainless steel welding only because of the small numbers. None of the organ-specific occurrences of congenital malformations were significantly increased among the children at risk from welding exposure. On the contrary, there was a marked deficit of cardiovascular malformations among the children at risk from both welding exposures and of genital malformations among the children at risk from mild steel welding (table 4).

\section{Childhood malignancy}

The observed number of children with malignant disease was very close to the number expected from national rates among both the children at risk and those not at risk from exposure (table 5). The four tumors among the children at risk from stainless steel or mild steel welding were two leukemia ( 0.65 expected, not significant), one brain tumor ( 0.62 expected, not significant), and Wilms kidney tumor ( 0.17 expected, not significant). In addition the overall incidence of cancer of children fathered by employees from the company cohort with unknown exposure status was as to be expected. However, in this group four cases of retinoblastoma occurred among nonsiblings (1.15 expected, relative risk $3.5,95 \%$ CI $1.1-8.4$ ).

\section{Discussion}

Initiated by several reports on reduced semen quality and fertility among welders, this study was undertaken to explore the hypothesis that welding is deleterious to spermatogenesis and increases delivery failures and the risk of childhood malignancy. We examined reproductive end points in a historical cohort of male Danish metalworkers generated for other purposes.

The prevalences of low birthweight, birth length, preterm delivery, death during first year of life, and congenital malformation were compared for pregnancies at risk and those not at risk from paternal welding exposure. The incidence of malignant disease in children at risk and those not at risk from paternal welding exposure prior to conception was compared with the national rate.

The prevalences of adverse delivery outcomes were essentially unaffected by paternal welding exposure. The finding of a slightly increased frequency of spontaneous abortion in pregnancies potentially at risk from paternal welding of stainless, but not mild, steel is the most striking observation although only suggestive of causal links to welding. Stainless steel welding fumes are highly mutagenic due to the content of hexavalent chromium (21) and might change the genetic material of sperm cells, which might in turn be associated with postimplantation loss. Unfortunately, the analysis of spontaneous abortion had several design limitations. First of all, spontaneous abortions were monitored conditionally on a subsequent birth. If stainless steel welding has a strong effect on abortion rate, a relatively smaller fraction of pregnancies are proceeding to birth, which might result in an underestimation of risk. On the other hand, women experiencing spontaneous abortion may be expected to achieve a new pregnancy faster than average, the result being a relatively high number of abortions in the years immediately preceding a birth. Nevertheless, it is difficult to imagine why this selection mechanism should act differentially, only affecting pregnancies at risk from stainless steel, but not from mild steel, welding. Second, the frequency of spontaneous abortion was distorted by a high frequency of induced abortions. The higher rate of induced abortions in pregnancies at risk from stainless steel welding (table 3 ) is, however, expected to result in a small underestimation of the risk estimate (28). The data gave no explanation of the difference in occurrence of induced abortions, which 
was probably not related to differences in age or socioeconomic status (table 1). Third, the risk estimates were blurred by a misclassification of exposure, which is expected to increase with time before the fix point, the child birth. The analysis including only births with either exposure or no exposure through all of the three preceding years revealed essentially the same risk estimate. Fourth, the validity of information on previous pregnancy outcomes obtained by the midwife at birth has not been documented, but we have no reason to believe that this information is inaccurate. Finally, the parameter estimates derived from the cumulative logistic model (odds ratio) are in this particular case expected to be very similar to those from a proportional hazard model [relative risk (29)].

Recall bias can be excluded altogether. Data on occupational exposure had been collected prior to the planning of this study, and information on outcome variables were obtained independently of the Birth Register. A few studies have reported an increased frequency of spontaneous abortion among the wives of exposed male workers $(7,11)$, but no studies of welders have so far been published.

Only limited information about the wives of the metalworkers was available, and in particular knowledge concerning life-style factors and medical histories was lacking. But major differences between the exposure groups were not expected because all of the women were wives of metalworkers and belonged to a probably very homogeneous socioeconomic stratum of the whole Danish population.

The finding of a marked deficit of birth defects among children at risk from mild steel welding was unexpected and is difficult to explain. The occurrence of congenital malformation was dependent on gender and the completeness of registration was dependent on age and follow-up time. In the analysis these phenomena were accounted for with a comparison of the age- and gender-specific rates adjusted for differences in followup time, not the crude prevalence measures. The inclusion of specialization of maternity ward (as probability of diagnosis of a birth defect depends on specialization of hospital department) and a number of other potential confounders in the logistic regression models did not change the risk estimates to any significant degree. The same results were obtained when only congenital malformations diagnosed at birth were included and when minor malformations such as hip dislocation and aures alatae were excluded from the analysis. When children at risk from both stainless steel and mild steel welding were considered, however, only a moderate and insignificant reduced occurrence was observed (OR 0.81, $95 \% \mathrm{CI} 0.57-1.15$; the number of children at risk from both mild and stainless steel welding being 1034). This finding makes it less likely that the reduced risk was attributable to the welding of mild steel per se, unless stainless steel welding antagonizes the action of mild steel welding or dilutes exposure to mild steel welding. Another study found reduced fertility among mild steel, but not stainless steel, welders (20). Alternatively, it might be hypothesized that conceptions occurring in spite of mild steel exposure develop to a survival population of fetuses with a reduced risk of congenital malformations. This a posteriori interpretation is speculative, and no definite conclusions can be drawn from this study. Only limited evidence about rare and highly specific malformations can be inferred from this study. The power to detect a three- and a fivefold increased risk of malformation with a background prevalence of $1 / 1000$ is 13 and $47 \%$, respectively. Welding was not associated with either a decrease or an increase of birth defects in a large-scale case-referent study exploring the relation between paternal occupation and congenital malformation (8).

The overall occurrence of malignant disease among children at preconceptional risk from welding was as to be expected from national rates. Several case-referent studies of Wilms' tumor reported case excesses in job groupings that included welders and machinists $(13,30,31)$. One case of Wilms' tumor (expected 0.17) was observed in a welder's child. However, no conclusions can be drawn regarding risk of specific tumors because of the small numbers. The power to detect a fivefold increase of risk for a rare disease occurring in 1 of 20000 children was only $45 \%$ at the 0.05 significance level in this study. The results of the cancer follow-up of the company cohort indicate that paternal employment in the metal industry is not associated with overall increased cancer risk in the offspring.

Children born before the father was admitted into the father cohort were excluded from the study base of metal workers so that conventions for follow-up studies could be complied with. Although previous reproductive experience may strongly influence the occupational status of a woman, this is, nevertheless, not likely to play any role among men. Reanalyses after inclusion of the 1669 children born before entrance of the father into the father cohort confirmed all of the reported results.

Another potential source of bias in this study was lack of independence among births of siblings. Restricting the analysis to delivery outcomes of first pregnancy again produced the same essentially negative results.

The follow-up period varied, spanning 0 to 11 years (congenital malformation) and 20 years (cancer). A possible change in welding exposure over time may in particular bias results of analyses of cancer incidence and late recognized congenital malformations. This source of bias, and potential bias as a result of time trends in occurrence and registration of outcomes under study, was accounted for by the inclusion of calendar time in the confounder analysis.

In conclusion, this study suggests that paternal stainless steel welding may be related to the occurrence of spontaneous abortion, and this association should be investigated in studies designed to test, in particular, 
this hypothesis. The overall occurrence of congenital malformation and childhood malignancy among children of welders was not elevated. These negative results should be interpreted cautiously because of the insufficient power to detect increased risk of highly specific malformations and childhood malignancies. However, in quantitative terms, the study does not suggest major deleterious impacts of paternal welding exposure on delivery outcomes and the occurrence of childhood cancer.

\section{Acknowledgments}

This study was supported by grants from the Danish Medical Research Council (JNR 12-7836 and 12$8999)$ and The Health Insurance Foundation (H 11/ 104-88). Professor J Olsen from the Institute of Epidemiology, University of Aarhus, is gratefully acknowledged for his valuable discussions of the methods.

\section{References}

1. Henderson J, Baker HGW, Hanna PJ. Occupationrelated male infertility: a review. Clin Reprod Fertil 1986;4:87-106.

2. Rosenberg MJ, Feldblum PJ, Marshall EG. Occupational influences on reproduction: a review of recent literature. J Occup Med 1987;29:584-91.

3. Brown NA. Are offspring at risk from their fathers' exposure to toxins? Nature $1985 ; 316: 110$.

4. Pearn JH. Teratogens and the male: an analysis with special reference to herbicide exposure. Med J Aust $1983 ; 2: 16-20$.

5. Arundel SE, Kinnier-Wilson LM. Parental occupations and cancer: a review of the literature. J Epidemiol Community Health 1986;40:30-6.

6. Olsen JH, Brown PN, Schulgen G, Jensen OM. Parental employment at time of conception and risk of cancer in offspring. Eur $\mathrm{J}$ Cancer. In press.

7. Taskinen $\mathbf{H}$, Anttila $\mathbf{A}$, Lindbohm $\mathbf{M}-\mathbf{L}$, Sallmén $\mathbf{M}$, Hemminki K. Spontaneous abortions and congenital malformations among the wives of men occupationally exposed to organic solvents. Scand $\mathbf{J}$ Work Environ Health 1989;15:345-52.

8. Andrew FO, Teschke K, Baird P. Paternal occupation and congenital anomalies in offspring. Am J Ind Med 1991;20:447-75.

9. Daniell WE, Vaughan TL. Paternal employment in solvent related occupations and adverse pregnancy outcomes. Br J Ind Med 1988;45:193-7.

10. Townsend JC, Bodner K, Van Peenen PFD, Olson RD Cook RR. Survey of reproductive events of wives of employees exposed to chlorinated dioxins. Am J Epidemiol 1982;115:695-713.

11. McDonald AD, McDonald JC, Armstrong B, Cherry NM, Nolin AD Robert D. Fathers' occupation and pregnancy outcome. Am J Occup Med 1989;46:329-33.

12. Gardner JM, Snee MP, Hall AJ, Powell CA, Downes
S Terrell JD. Results of case-control study of leukaemia and lymphoma among young people near Sellafield nuclear plant in West Cumbria. Br Med J 1990;300: $423-9$.

13. Bunin GR, Nass CC, Kramer S, Meadows AT. Parental occupation and Wilms' tumor: results of a casecontrol study. Cancer Res 1989;49:725-9.

14. Bunin GR, Ward E, Kramer S, Rhee CA, Meadows AT. Neuroblastoma and parental occupation. Am J Epidemiol 1990;131:776-80.

15. Furuhjelm M, Jonson B, Lagergren CG. The quality of human semen in spontaneous abortion. Int $\mathbf{J}$ Fertil 1962;7:17-21.

16. Joel CA. New etiologic aspects of habitual abortion and infertility, with special reference to the male factor. Fertil Steril 1966;17:374-80.

17. Mortensen JT. Risk for reduced sperm quality among metal workers, with special reference to welders. Scand J Work Environ Health 1988;14:27-30.

18. Bonde JP. Semen quality and sexual hormones among mild steel and stainless steel welders: a cross-sectional study. Br J Ind Med 1990;47:508-14.

19. Rachootin P, Olsen J. The risk of infertility and delayed conception associated with exposures in the Danish workplace. J Occup Med 1983;25:394-402.

20. Bonde JP, Hansen KS, Levine RD. Fertility among Danish male welders. Scand J Work Environ Health 1990; 16:315-22.

21. Stern RM. Process-dependent risk of delayed health effects for welders. Environ Health Perspect 1981;41: $235-53$.

22. International Agency for Research on Cancer (IARC). Chromium, nickel and welding. Lyon: IARC, 1990. (IARC monograph on the evaluation of carcinogenic risks to humans; vol 49).

23. Danmarks Statistik. Statistisk tiarsoversigt [Ten year statistical review] Copenhagen: Danmarks Statistik, 1988.

24. Shaw GM, Gold EB. Methodological considerations in the study of parental occupational exposures and congenital malformations in offspring. Scand J Work Environ Health 1988;14:344-55.

25. Jensen OM. Cancer morbidity and causes of death among Danish brewery workers. Lyon: International Agency for Research on Cancer, 1980.

26. SAS Institute Inc. SAS/STAT, users' guide, version 6; vol 2. 4th ed. Cary, NC: SAS Institute Inc, 1989.

27. Rothman KJ, Boice JD Jr. Epidemiologic analysis with a programmable calculator. Boston, MA: Epidemiology Resources, Inc, 1982.

28. Olsen $\mathrm{J}$. Calculating risk ratios for spontaneous abortions: the problem of induced abortions. Int J Epidemiol 1984;13:347-50.

29. Ingram DD, Kleinman JC. Empirical comparisons of proportional hazards and logistic regression models. Stat Med 1989;8:525-38.

30. Kantor A, McCrea Curnen MG, Meigs JW, Flannery JT. Occupations of fathers of patients with Wilms' tumour. J Epidemiol Community Health 1979;33: 253-6.

31. Sew-Leong K, Lawrence JF. The association between parental occupation and childhood malignancy. J Occup Med 1980;22:792-4.

Received for publication: 26 August 1991 